\title{
Cerâmicas odontológicas: o estado atual
}

\section{(Ceramic in dentistry: current situation)}

\author{
E. A. Gomes, W. G. Assunção, E. P. Rocha, P. H. Santos \\ R. José Bonifácio, 1193, Vila Mendonça, Araçatuba, SP \\ ericaagomes@yahoo.com.br
}

\begin{abstract}
Resumo
As cerâmicas dentais são conhecidas pela sua excelência em reproduzir artificialmente os dentes naturais. No século XVIII foi empregada pela primeira vez na Odontologia como dente artificial para próteses totais. A partir do século XX passou a ser utilizada para a confecção de restaurações metalocerâmicas e mais recentemente, com o aprimoramento da tecnologia cerâmica, surgiram as restaurações livres de metal. As cerâmicas têm apresentado rápida evolução em âmbito científico com o intuito de melhorar suas propriedades físicas e mecânicas para suprir as necessidades estéticas que são cada vez mais exigidas pela sociedade moderna. Nesse contexto, é preciso conhecer cada sistema cerâmico disponível atualmente no mercado, desde suas principais características até suas limitações, para saber indicá-lo de modo correto em cada situação clínica específica.
\end{abstract}

Palavras-chave: cerâmica, ligas metal-cerâmica.

\begin{abstract}
Dental ceramics are known for their excellence in artificially reproduce natural teeth. In the XVIII century they were employed for the first time in Dentistry as artificial tooth for complete dentures. Since the XX century they were used to fabricate metal ceramic restorations and, nowadays, all-ceramic restorations are obtained as a result of ceramic technology improvement. Ceramics present a fast progress in the scientific field in order to improve their physical and mechanical properties to provide for aesthetic needs so required by modern society. In this context, it is important to know each ceramic system currently available on the market, regarding not only its main features but also its limitations, to an accurate indication for each specific clinical situation.
\end{abstract}

Keywords: ceramics, metal-ceramic alloys.

\section{INTRODUÇÃO}

A cerâmica odontológica também denominada porcelana dental é conhecida por ser um material de aparência semelhante ao dente natural, devido sua adequada propriedade óptica e durabilidade química. Estas e outras qualidades, como excelente estética e dureza, possibilitaram o rápido desenvolvimento deste material no contexto científico quanto às suas propriedades, com o objetivo básico de tentar satisfazer o crescente aumento da exigência estética preconizada pela sociedade moderna.

A palavra cerâmica é originária da palavra grega keramos que significa argila. Dados encontrados a quase 13 mil anos mostram evidências dos primeiros indícios de cerâmica nas escavações do Vale do Nilo, Egito. Desde o século X, a China já dominava a tecnologia da arte em cerâmica, a qual apresentava estrutura interna firme e cor muito branca, chegando na Europa apenas no século XVII onde ficou conhecida como "louças de mesa". A partir de então, muito esforço por parte dos europeus foi dispensado a fim de copiar a composição da porcelana chinesa. Entretanto, somente em 1717 é que se descobriu o segredo dos chineses, que confeccionavam a cerâmica a partir de três componentes básicos: caulim (argila chinesa), sílica (quartzo) e feldspato (mistura de silicatos de alumínio, potássio e sódio) [1].
Assim, em 1720 os europeus desenvolveram uma porcelana fina e translúcida comparável à porcelana chinesa, composta por feldspato e óxido de cálcio como fundente, sendo que a queima era realizada em alta temperatura [2].

Em 1774 o francês Alexis Duchateau, insatisfeito com sua prótese total confeccionada com dentes de marfim, decidiu trocá-las por novas próteses de cerâmica, por verificar a durabilidade e resistência ao manchamento e a abrasão deste material quando utilizado em utensílios domésticos. Com o auxílio de Nicholas Dubois de Chemant, a arte das cerâmicas foi introduzida na Odontologia [2].

No final do século XIX surgiram as próteses parciais fixas em cerâmica, denominadas de coroas de jaquetas, que passaram a ser amplamente utilizadas, desde que foi patenteada e desenvolvida a técnica da folha de platina [3]. Em 1950, adicionou-se leucita na formulação da porcelana visando aumentar o coeficiente de expansão térmica e possibilitar sua fusão com certas ligas áureas para confecção de coroas totais e próteses parciais fixas (PPFs) [2].

Foram desenvolvidas na Inglaterra as porcelanas feldspáticas, às quais foram incorporadas 40 a $50 \%$ de cristais de alumina, com o objetivo de melhorar a resistência das coroas de jaqueta (120 a $180 \mathrm{MPa})$ sem sacrificar a estética [4]. Em 1976 uma nova técnica foi introduzida para aumentar ainda mais a resistência das coroas de jaqueta em 
alumina [5]. Para isso utilizaram uma folha de platina sobre a qual tinha uma camada de óxido de estanho, responsável em promover a união entre a porcelana e a folha de platina.

Diante desta evolução, no fim do século $\mathrm{XX}$, diversos sistemas inovadores foram introduzidos no mercado, a fim de proporcionar a confecção de restaurações cerâmicas livres de metal. A partir de então, vários sistemas cerâmicos foram desenvolvidos, sempre com o intuito de melhorar as propriedades físicas e mecânicas do material. Assim, o objetivo desse trabalho foi realizar uma revisão na literatura visando mostrar uma breve história da cerâmica dental, composição dos diversos sistemas e estrutura básica, além de enfatizar as principais características e limitações das porcelanas odontológicas mais atuais.

\section{Revisão de Literatura}

\section{Composição e estrutura das cerâmicas odontológicas}

As cerâmicas odontológicas são compostas por elementos metálicos (alumínio, cálcio, lítio, magnésio, potássio, sódio, lantânio, estanho, titânio e zircônio) e substâncias não metálicas (silício, boro, flúor e oxigênio) [1] e caracterizadas por duas fases: uma fase cristalina circundada por uma fase vítrea. A matriz vitrosa é composta por uma cadeia básica de óxido de silício $\left(\mathrm{SiO}_{4}\right)$, sendo que a proporção $\mathrm{Si}: \mathrm{O}$ está relacionada com a viscosidade e expansão térmica da porcelana [1]. Já a quantidade e natureza da fase cristalina ditam as propriedades mecânicas e ópticas [6]. Além disso, a formulação da porcelana deve ser feita de modo a apresentar propriedades, como fundibilidade, moldabilidade, injetabilidade, usinabilidade, cor, opacidade, translucidez, resistência à abrasão, resistência e tenacidade à fratura [1].

A microestrutura das porcelanas, que se refere à natureza, tamanho, forma, quantidade e distribuição estrutural dos elementos, exerce significante efeito nas propriedades físicas das mesmas, sendo dependente das condições de sinterização de cada fase da cerâmica, o qual ditará propriedades como coeficiente de expansão térmica, valores de resistência, solubilidade química, transparência e aparência [7]. O padrão de superfície estrutural das porcelanas foi avaliado de acordo com o tipo de condicionamento ácido aplicado, microestrutura e composição de 15 cerâmicas [7]. Verificaram que as diferenças na microestrutura e na composição das cerâmicas são fatores que controlam o desenvolvimento de retenção micromecânica produzida por qualquer dos 3 ácidos testados, sendo o amônio bifluorídrico, ácido hidrofluorídrico a 9,6\% e ácido flurido-fosfórico a $4 \%$.

As cerâmicas dentais são conhecidas pela sua excelente propriedade em reproduzir as características dos dentes naturais, por ser altamente durável, de ampla aceitação tanto do profissional quanto do paciente, biocompatibilidade, natureza refratária, inércia química, friabilidade e baixa resistência à tração, sendo que diversos estudos realizados visam melhorar a resistência à fratura das cerâmicas, destacando-se a união a metais (restaurações metalcerâmicas), união a finos casquetes de ouro ou de platina via deposição de camada de estanho, trocas iônicas (Tufcoat), inclusão de alumina ou zircônia nas cerâmicas para infra-estrutura (In-Ceram Alumina, In-Ceram Zircônia e InCeram Spinel), cerâmicas termo-injetáveis (IPS Empress), cerâmicas com alta densidade de alumina (Sistema Procera), cerâmicas de fundição (Cera Pearl, Olympus, Dicor e Dicor Plus) e adesão direta à estrutura dentária (facetas, onlays e inlays).

Atualmente a classificação mais utilizada para as cerâmicas dentais é aquela que as define de acordo com sua fase cristalina em feldspática, reforçada por leucita, aluminizada, com alto conteúdo de alumina, de zircônia e espinélio infiltrada por vidro, cerâmica vítrea e alumina densamente sinterizada.

\section{Cerâmica feldspática}

A porcelana feldspática é definida como um vidro, composta por feldspato de potássio $\left(\mathrm{K}_{2} \mathrm{O}_{2} \mathrm{Al}_{2} \mathrm{O}_{3} 6 \mathrm{SiO}_{2}\right)$ e pequenas adições de quartzo $\left(\mathrm{SiO}_{2}\right)$, sendo que em altas temperaturas, o feldspato decompõe-se numa fase vítrea com estrutura amorfa e numa fase cristalina constituída de leucita $\left(\mathrm{KAlSi}_{2} \mathrm{O}_{6}\right.$ ou $\mathrm{K}_{2} \mathrm{O}_{2} \cdot \mathrm{Al}_{2} \mathrm{O}_{3} \cdot 4 \mathrm{SiO}_{2}$ ) [6]. Pode ser classificada de acordo com sua temperatura de fusão em: porcelana de alta fusão $\left(>1300^{\circ} \mathrm{C}\right)$, média fusão $(1101-1300$ $\left.{ }^{\circ} \mathrm{C}\right)$, baixa fusão $\left(850-1100{ }^{\circ} \mathrm{C}\right)$ e ultrabaixa fusão $(650-850$ $\left.{ }^{\circ} \mathrm{C}\right)$ [8]. Sua indicação visa à confecção de coroas de jaqueta de diversos tipos (camada de opaco, corpo de dentina, dentina gengival, overlay de esmalte e esmalte incisal) [9], restaurações metalocerâmicas e totalmente cerâmicas com baixo conteúdo de leucita (coroas, inlays, onlays e facetas laminadas) [10].

\section{Cerâmica associada a metais}

A fim de possibilitar a associação das porcelanas aos metais, viabilizando a confecção de restaurações metalcerâmicas, foi necessário incorporar maior concentração de leucita nas porcelanas feldspáticas para aumentar o coeficiente de expansão térmica, tornando-o semelhante ao das ligas fundidas, minimizando o estresse térmico residual.

As cerâmicas utilizadas para a confecção de restaurações metal-cerâmicas possuem translucidez semelhante aos dentes, são resistentes à compressão, apresentam baixa temperatura de fusão, o que diminui o potencial de distorção do coping metálico, não corroem e são resistentes aos fluidos orais. No entanto, apresentam baixa resistência à flexão (60 $\mathrm{MPa}$ ) e elevada dureza, a qual poderá provocar abrasão dos dentes opostos [6]. São indicadas como material para faceta das coroas metal-cerâmicas e próteses parciais fixas.

A união metal-cerâmica é derivada basicamente de três princípios: molecular (óxidos formados na superfície do metal agem como componente de união permanente, formando uma estrutura sanduíche, a qual é unida separadamente tanto ao substrato do metal como da porcelana), mecânico (a rugosidade de superfície produzida pelo jateamento 
promove retenção mecânica e aumenta a área superficial para a união com a porcelana) e união de compressão (o coeficiente de expansão térmico das facetas de porcelana são discretamente mais baixo que da liga metálica para assegurar que a cerâmica esteja sob baixa compressão após o esfriamento) $[5,6]$.

A sobrevivência das PPFs metal-cerâmicas em diferentes períodos foi avaliada [11], sendo que em 5 anos de instalação a sobrevida das próteses foi de $96 \%$, em 10 anos de $87 \%$ e em 15 anos de $85 \%$. A principal razão de falhas esteve relacionada com a fratura dental $(38 \%)$, doença periodontal $(27 \%)$, perda do retentor $(13 \%)$ e cárie $(11 \%)$. Outras principais falhas também relacionadas são a soltura da faceta cerâmica, dissolução do cimento e fratura radicular [12].

\section{Cerâmica Dicor}

A cerâmica Dicor, introduzida em 1980, é uma cerâmica de fundição, sendo um dos primeiros sistemas cerâmicos que empregou tecnologia mais apurada, composta por vidro contendo $45 \%$ de cristais de mica tetrasílica com flúor, obtida pelo processo convencional de cera perdida e vidro fundido de 1350 a $1400{ }^{\circ} \mathrm{C}$ [10], resultando numa restauração de cerâmica vítrea que apresenta certo grau de contração. Adicionalmente, mostra-se com qualidade estética aceitável e mais resistente que as demais porcelanas, com resistência de aproximadamente 90 a $120 \mathrm{MPa}$ [13]. Além disso, apresenta baixo módulo de elasticidade, reduzido coeficiente de expansão e pequena resistência à dureza. Esse sistema era indicado para a confecção de coroas unitárias anteriores e posteriores, inlays, onlays e facetas laminadas [10], sendo atualmente seu uso pouco empregado. As coroas de vidro fundível mostravam boa performance clínica quando era mantida uma espessura adequada de material na superfície oclusal [14] e alta taxa de fratura em regiões posteriores (3564\%) [13].

\section{Sistema cerâmico infiltrado por vidro - Sistema In- Ceram}

A cerâmica In-Ceram (Vita Zahnfabrik, Bad Sackingen, Alemanha) foi desenvolvida visando melhorar os problemas relacionados com a resistência a fratura e tenacidade. Sua composição consiste em 2 fases tridimensionais interpenetradas: uma fase de alumina (óxido de alumínio) e uma fase vítrea (à base de óxido de lantânio), sendo sua confecção baseada em alumina porosa que, posteriormente, é infiltrada por vidro. A resistência à tensão para o núcleo de cerâmica In-Ceram é 3 a 4 vezes melhor quando comparado à outras cerâmicas dentais $[15,16]$. Com relação à adaptação marginal das restaurações obtidas a partir deste sistema temse até $24 \mu \mathrm{m}$ de desadaptação para as coroas unitárias e $58 \mu \mathrm{m}$ para as PPFs $[17,18]$. Este sistema apresenta três variáveis, de acordo com o seu principal componente: alumina $\left(\mathrm{Al}_{2} \mathrm{O}_{3}\right)$ - In-Ceram Alumina, spinel $\left(\mathrm{MgAl}_{2} \mathrm{O}_{4}\right)$ - In-Ceram Spinel e zircônia $\left(\mathrm{Al}_{2} \mathrm{O}_{3} \mathrm{ZrO}_{2}\right)$ - In-Ceram Zircônia. A In-Ceram Alumina (Vita Zahnafabric, Bad Sackingen, Germany) apresenta em sua composição conteúdo de alumina variando entre 70 e $85 \%$ com resistência flexural de 236-600 MPa $[15,16]$ e resistência à fratura de $3,1-4,61 \mathrm{MPa} / \mathrm{m}^{1 / 2}[19$, 20]. Esse sistema é indicado para coroas unitárias anteriores e posteriores, sendo o primeiro a confeccionar PPF de 3 elementos totalmente cerâmicos para a região anterior até canino [1,21]. Entretanto, é necessária uma dimensão mínima para o conector, sendo preconizada $4 \mathrm{~mm}$ para o sentido ocluso-gengival (OG) e $3 \mathrm{~mm}$ para o vestíbulolingual (VL) [22]. O sistema In-Ceram Zircônia é composto de cerâmica a base de alumina infiltrada por vidro, reforçada por óxido de zircônio $\left(\mathrm{ZrO}_{2}\right)$, cerca de $30-35 \%$, o que proporciona maior resistência à flexão (421-800 MPa) [19, 20], à fratura $\left(6-8 \mathrm{MPa} / \mathrm{m}^{1 / 2}\right)$ [23] e opacidade semelhante às ligas metálicas [24], característica esta que contra-indica a confecção de PPF para a região anterior, onde a translucidez do material é o fator responsável pela estética. É indicado para coroa unitária posterior sobre dentes naturais ou sobre implantes posteriores e PPF posterior de três elementos, sendo necessário que o conector apresente uma dimensão mínima de 4-5 mm no sentido OG e 3-4 mm para o sentido VL [22]. A cerâmica In-Ceram Spinel contém o espinélio de magnésio como principal fase cristalina, com traços de alfa-alumina que proporciona melhora na translucidez da restauração, devido ao baixo índice de refração do aluminato de magnésio e da matriz vítrea. Apresenta resistência à flexão variando de 280 a $380 \mathrm{MPa}$ [15], sendo indicado para restaurações coronárias parciais e coroas unitárias anteriores $[1,6]$.

Estudos longitudinais mostram a sobrevivência de $88 \%$, em 5 anos, de 36 PPFs confeccionadas com o sistema InCeram Alumina [25]; 94,4\% de sucesso, em 3 anos, de 18 PPFs de In-Ceram Zircônia [26]; 99,1\% de sobrevivência de 546 coroas In-Ceram colocadas tanto na região anterior como na região posterior durante um período de 6 anos [27]. As poucas falhas clínicas observadas foram relacionadas as PPFs, com origem na região dos conectores e interface entre o núcleo cerâmico e faceta de porcelana. Outras causas para o insucesso das restaurações In-Ceram são o núcleo delgado no aspecto vestibular para a região anterior e excessiva força oclusal parafuncional na região posterior [27].

\section{Sistemas cerâmicos prensados - Sistema IPS Empress}

O sistema IPS Empress (Ivoclar North América, Amherst, NY, EUA) é baseado em cerâmica vítrea reforçada por cristais de leucita (35-55\% - Sistema IPS Empress I - E1) ou reforçada por cristais de dissilicato de lítio (6065\% - Sistema IPS Empress II - E2), no qual a cerâmica é injetada num molde de revestimento, obtido pela técnica da cera perdida, sob alta temperatura e pressão. Para o E1 a cerâmica é prensada numa temperatura de 1150 - $1180{ }^{\circ} \mathrm{C}$, enquanto no E2 é injetada a 890 - $920^{\circ} \mathrm{C}$ [6]. O IPS Empress simplificou o problema de contração durante a queima da cerâmica, comum para as feldspáticas, devido à alta pressão de injeção da cerâmica no molde em alta temperatura [28]. Desta maneira, a variação dimensional somente 
ocorre durante o resfriamento, que pode ser controlada por adequada expansão do revestimento. Esta técnica de pressão pelo calor tem proporcionado o aumento na resistência da cerâmica IPS Empress, o qual também está relacionado com o subseqüente tratamento com calor durante a queima da faceta [28], resultado de queimas múltiplas devido ao aumento de leucita [29] ou dissilicato de lítio. O sistema IPS Empress 1 apresenta resistência flexural variando entre 97 a $180 \mathrm{MPa}$ [15], enquanto o IPS Empress 2 de 300 - $400 \mathrm{MPa}$ [30]. Esse sistema é indicado para a confecção de coroas de cerâmica puras unitárias anterior e posterior, inlays, onlays, facetas e, mais recentemente, a utilização do sistema IPS Empress II para a confecção de PPF de 3 elementos para dente anterior até $2^{\circ}$ pré-molar. Entretanto, existe uma dimensão mínima crítica para cada conector, sendo de 4 - 5 mm para o sentido OG e de 3 - 4 mm para o sentido VL [31]. Verificou-se com este sistema uma razão de $93 \%$ de sucesso, em 2 anos, para 30 PPFs confeccionadas com o sistema Empress II [32], sendo que a principal razão das falhas esteve relacionada com a fratura do conector para as PPFs metal free [33]. Observaram também, falhas na superfície de cimentação, pois esta é uma região de alta tensão de estresse tendo uma espessura crítica que necessita ser resistente [2].

Outros sistemas disponíveis são: OPC e OPC 3G (Jeneric/Pentron, Wallingford), Vision Esthetic (Wohlwend), VitaPress (VITA), Finesse (Dentsply/Ceramco), Cergogold (DeguDent).

\section{Sistemas cerâmicos fresados}

A usinagem é uma opção a ser utilizada como método de fabricação de restaurações cerâmicas metal free para inlays, onlays, facetas e PPF. Dentre os sistemas de fresagem disponíveis comercialmente têm-se: CEREC 1, 2 e 3 (Sirona), CELAY (VITA Zahnfabrik), Procera (Nobel Biocare), Cercon (Dentsply/Ceramco), Lava All-Ceramic System (3M/ESPE) e sistema CAD/CAM (Computer Assisted Design - Computer Assisted Manufature).

a) Sistema Cerec e Celay: O sistema Cerec faz a captação da imagem do preparo diretamente da cavidade bucal com o auxílio de uma microcâmera, que seqüencialmente é processada pela unidade CAD para que possa ser planejada e executada a restauração, auxiliada pelo computador CAM. Já no sistema In Ceram Celay, a fresagem é realizada a partir de um bloco cerâmico, contendo de 70-85\% de partículas de alumina [34]. Embora a usinagem reduza a resistência das cerâmicas confeccionadas a partir do sistema Cerec e Celay, há relatos que a resistência de ambos os tipos de cerâmica são iguais ou superiores à resistência normalmente relatada para equivalentes cerâmicas dentais confeccionadas em laboratório [2]. O principal problema relatado com a utilização desses sistemas consiste na adaptação marginal insatisfatória, com valores de desadaptação variando entre 100 a $150 \mu \mathrm{m}$, sendo que a adaptação marginal da cerâmica Celay é melhor que do sistema Cerec. A grande vantagem em utilizar tais métodos consiste na possibilidade de obtenção de elementos cerâmicos unitários em apenas uma consulta, pois os copings para coroa unitária e infra-estrutura para PPF simples são usinadas a partir de blocos com a máquina Celay e então infiltrados, onde o tempo de infiltração é de poucos minutos comparado com $4 \mathrm{~h}$ de laboratório dental para a cerâmica In-Ceram.

b) SistemaProceraAllCeram:O sistemaProceraAllCeram é composto por alto conteúdo de alumina pura $(99,9 \%$ de $\mathrm{Al}_{2} \mathrm{O}_{3}$ ), densamente sinterizada, utilizando tecnologia CAD/ CAM, sendo que a configuração da restauração é enviada para a fábrica na Suécia. O óxido de alumínio utilizado pelo sistema Procera segue as exigências da ISO 6474 quanto à densidade, tamanho do grânulo e resistência flexural [35]. Apresenta excelente biocompatibilidade, resistência à flexão variando de 487-699 MPa e resistência à fratura entre 4,48$6,0 \mathrm{MPa} / \mathrm{m}^{1 / 2}$ [19]. É indicado para a confecção de casquetes para coroas unitárias anterior e posterior, PPF de 3 elementos com retentor distal até $1^{\circ}$ molar [1], sendo que a dimensão mínima recomendada para o conector deve ser de $3 \mathrm{~mm}$ de altura e $2 \mathrm{~mm}$ de largura [36]. Também pode ser utilizado para a confecção de supra-estruturas unitárias para prótese sobre implante [35]. Esse sistema apresenta características mecânicas diferenciadas em relação aos demais sistemas citados anteriormente, mas ainda há certa insegurança quanto sua cimentação adesiva [37]. Quanto à longevidade do tratamento, foi verificada uma sobrevivência de 96,9 para $97 \%$ casos de restaurações utilizando o sistema Procera AllCeram tanto para a região anterior como para a posterior, num período de 5 anos [38].

c) Cerâmica à base de zircônia tetragonal policristalina estabilizada com itria (Y-TZP): Inicialmente este material foi empregado na área médica pelos ortopedistas com relevante sucesso devido as excelentes propriedades mecânicas do material e biocompatibilidade [39]. Atualmente, tornouse uma opção viável para a confecção de núcleos para restaurações totalmente cerâmicas e PPF [40], sendo que os sistemas Cercon (DeguDent) e Lava All-Ceramic System (3M/ESPE) utilizam esse tipo de cerâmica, no qual as restaurações são confeccionadas pelo procedimento de fresagem. O óxido de ítrio é adicionado na zircônia pura com o objetivo de estabilizar a fase cúbica ou tetragonal na temperatura ambiente, gerando um material polifásico conhecido como zircônia estabilizada. A estabilização na fase tetragonal é responsável pela alta tenacidade à fratura da Y-TZP [41]. A Y-TZP não possui fases vítreas devido à microestrutura policristalina, o que evita o fenômeno de sua degradação ou desestabilização pela saliva e conseqüente aumento da propagação de trincas [42]. Apresenta resistência à flexão maior em relação aos demais sistemas cerâmicos, variando de 900 a $1200 \mathrm{MPa}$, e resistência à fratura em torno de 9-10 MPa/m ${ }^{1 / 2}$ [43]. Devido a estas características mecânicas, os conectores podem apresentar menor área comparada com os demais materiais para núcleo totalmente cerâmico, podendo variar de 7 a $16 \mathrm{~mm}^{2}$. Com o sistema Cercon (DeguDent) há a possibilidade de confeccionar coroas anteriores e posteriores e PPF de 3 a 8 elementos, 
sendo que em um período de avaliação de 5 anos observouse $100 \%$ de sucesso clínico e em 1 ano foi observado $100 \%$ de sucesso para PPF posterior de 3 e 4 elementos [10]. Já o sistema Lava utiliza a tecnologia CAD/CAM para a confecção de coroas unitárias anteriores e posteriores e PPF de 3 a 4 elementos e, segundo o fabricante, em 3 anos de estudo nenhuma fratura ocorreu em 150 PPF [44].

\section{DISCUSSÃO}

Na Tabela I é exposto um resumo das características e indicações dos principais sistemas cerâmicos acima mencionados.

Juntamente com a evolução dos sistemas cerâmicos observa-se uma melhora nas propriedades mecânicas destes materiais, possibilitando desde a confecção de restaurações unitárias até mesmo a confecção de PPFs livres de metal ou metal free. Cada sistema apresenta particularidades quanto à confecção e composição da cerâmica. Conforme o componente presente na fase cristalina, há uma alteração na resistência mecânica possibilitando a confecção de PPF metal free de até 8 elementos.

O material ideal para a confecção de coroas artificiais deve possibilitar o controle de cor do substrato (matiz, croma e valor) e da sua translucidez. Entretanto, nenhum sistema cerâmico apresenta tal flexibilidade. As cerâmicas que possuem a adição de zircônia em sua composição são os materiais que oferecem menor grau de translucidez, dificultando sua utilização para restaurações anteriores [24].

Avaliando algumas propriedades mecânicas dos sistemas cerâmicos IPS Empress, In-Ceram e Procera AllCeram verificou-se que esses materiais apresentam maior resistência à flexão e dureza comparada com as porcelanas feldspáticas convencionais utilizadas para a confecção das coroas de jaqueta, sendo que a cerâmica In-Ceram apresenta menor resistência flexural que a Procera AllCeram, porém mostra resistência a fratura semelhante ao sistema comparado. A elevada dureza da In-Ceram é o resultado da segunda fase de reforço dado pela alumina, que provavelmente torna mais difícil a propagação de trincas [19].

Entretanto, igualmente às restaurações metal-cerâmicas, as restaurações livres de metal também podem trazer o insucesso para a restauração. A causa primária de falha relatada para as PPFs totalmente cerâmicas difere das PPF metalocerâmicas. Para as totalmente cerâmicas, a falha ocorre normalmente na região do conector levando à sua fratura [45] e nas metalocerâmicas, a falha ocorre com o desenvolvimento de trincas na superfície de entalhe do pôntico.

A dimensão mínima para o conector das PPF metalcerâmicas deve ser de pelo menos $2,5 \mathrm{~mm}$ no sentido OG e $6,25 \mathrm{~mm}$ no sentido VL, tanto para a região anterior como para a posterior [46]. Para as totalmente cerâmicas, devido ao modo de falha e friabilidade, os conectores requerem maior largura que as metal-cerâmicas. Assim, as PPFs totalmente cerâmicas devem ser contra-indicadas para espaço insuficiente do conector [33].

Um elevado sucesso é observado com as coroas totalmente cerâmicas quando se utiliza um protocolo correto quanto ao preparo do dente, espessura adequada de suporte para o núcleo cerâmico e ajuste oclusal correto da peça instalada. Além disso, a qualidade e durabilidade da união entre o material e o dente também garantem o sucesso clínico das restaurações cerâmicas, sendo que a microestrutura e a composição da cerâmica tem um significante efeito na resistência à fratura da união dentina-coroa cerâmica. Tem sido mostrado que diferentes superfícies topográficas são produzidas de acordo com o tipo de condicionamento e microestrutura cerâmica $[7,47]$.

Para as cerâmicas feldspáticas, o condicionamento da superfície com ácido hidrofluorídrico e o jateamento da superfície com óxido de alumínio são meios eficazes na promoção de união mecânica ao agente cimentante resinoso e a silanização é um método que proporciona a união química entre a fase inorgânica da cerâmica e a fase orgânica do material resinoso aplicado sobre a superfície cerâmica condicionada [10].

O cimento resinoso melhora o comportamento mecânico de sistemas cerâmicos, como IPS Empress I e II, Dicor e restaurações fresadas com os blocos cerâmicos, após o condicionamento com ácido hidrofluorídrico ou jateamento com partículas de óxido de alumínio (50 $\mu \mathrm{m})$ [1]. Entretanto, as cerâmicas que apresentam como componente principal os óxidos de alumínio e zircônio (InCeram, Procera, Cercon, Lava), o condicionamento com ácido fluorídrico e jateamento com partículas de óxido de alumínio não se mostra eficiente, devido a ausência da fase vítrea e redução do conteúdo de sílica. Assim, podem ser utilizados métodos alternativos para proporcionar uma adequada união desses materiais, como o jateamento com óxido de alumínio em combinação com cimento resinoso contendo monômeros fosfato (Panavia Ex) ou tratamento com Rocatec para o InCeram [48]; combinação de silanização, tratamento com sistema Rocatec e cimento resinoso para o sistema Procera AllCeram [10].

As coroas Procera AllCeram podem ser cimentadas definitivamente pela maneira convencional utilizando cimento de fosfato de zinco ou cimento de ionômero de vidro ou adesivamente com resina composta autopolimerizável. Entretanto, o fosfato de zinco apresenta uma translucidez menor que o cimento de ionômero de vidro, o que influencia nas características ópticas das restaurações totalmente cerâmicas [35].

Dificuldades são encontradas em avaliar de maneira conclusiva as diferentes técnicas de cimentação adesiva, pois não se tem muito estudo clínico em longo prazo sobre o referido tópico. Além disso, é clinicamente importante o fato que a criação de um ambiente seco por meio do uso de um lençol de borracha é impossível, ou possível com considerável dificuldade, se as margens do preparo estiverem localizadas subgengivalmente. Assim, vários autores atualmente preferem utilizar a cimentação convencional com cimento de fosfato de zinco ou cimento de ionômero de vidro [35]. 
Tabela I - Principais características e indicações dos diferentes sistemas cerâmicos. [Table I - Main characteristics and indications of the different ceramic systems.]

\begin{tabular}{|c|c|c|c|c|}
\hline Sistema cerâmico & $\begin{array}{l}\text { Nome } \\
\text { comercial }\end{array}$ & Material do núcleo & $\begin{array}{l}\text { Resistência à } \\
\text { flexão } \\
(\mathrm{MPa})\end{array}$ & Indicação \\
\hline $\begin{array}{l}\text { Cerâmica } \\
\text { Feldspática }\end{array}$ & --- & $\begin{array}{l}\text { Feldspato com adição } \\
\text { de leucita }\end{array}$ & $46,4-66,7$ & $\begin{array}{l}\text { Coroa unitária anterior e } \\
\text { posterior e PPF. }\end{array}$ \\
\hline $\begin{array}{l}\text { Cerâmica de } \\
\text { Fundiçãao }\end{array}$ & Dicor & $\begin{array}{l}\text { Vidro contendo } 45 \% \\
\text { de cristais de mica } \\
\text { tetrasílica com flúor }\end{array}$ & $90-120$ & $\begin{array}{c}\text { Coroa unitária anterior e } \\
\text { posterior, inlay, onlay e faceta. }\end{array}$ \\
\hline $\begin{array}{l}\text { Sistema cerâmico } \\
\text { prensado }\end{array}$ & IPS Empress I & $\begin{array}{l}\text { Cerâmica vítrea } \\
\text { reforçada por leucita }\end{array}$ & $97-180$ & $\begin{array}{c}\text { Coroa unitária anterior e } \\
\text { posterior, inlay, onlay e faceta. }\end{array}$ \\
\hline $\begin{array}{l}\text { Sistema cerâmico } \\
\text { prensado }\end{array}$ & IPS Empress II & Dissilicato de lítio & $300-400$ & $\begin{array}{c}\text { Coroa unitária anterior e } \\
\text { posterior, inlay, onlay, faceta, } \\
\text { PPF de } 3 \text { elementos (até } 2^{\circ} \mathrm{PM} \text { ) }\end{array}$ \\
\hline $\begin{array}{l}\text { Sistema cerâmico } \\
\quad \text { infiltrado }\end{array}$ & $\begin{array}{l}\text { In-Ceram } \\
\text { Alumina }\end{array}$ & $\begin{array}{l}\text { Cerâmica vítrea } \\
\text { infiltrada por alumina }\end{array}$ & $236-600$ & $\begin{array}{l}\text { Coroa unitária anterior e } \\
\text { posterior, PPF de } 3 \text { elementos } \\
\text { (incisivo central a canino). }\end{array}$ \\
\hline $\begin{array}{l}\text { Sistema cerâmico } \\
\quad \text { infiltrado }\end{array}$ & $\begin{array}{l}\text { In-Ceram } \\
\text { Zircônia }\end{array}$ & $\begin{array}{l}\text { Cerâmica vítrea } \\
\text { infiltrada por } \\
\text { alumina e partículas } \\
\text { estabilizadoras de } \\
\text { zircônia }\end{array}$ & $421-800$ & $\begin{array}{l}\text { Coroa unitária posterior sobre } \\
\text { dentes naturais ou implante e } \\
\text { PPF posterior de } 3 \text { elementos. }\end{array}$ \\
\hline $\begin{array}{l}\text { Sistema cerâmico } \\
\quad \text { infiltrado }\end{array}$ & $\begin{array}{l}\text { In-Ceram } \\
\text { Spinel }\end{array}$ & $\begin{array}{c}\text { Cerâmica vítrea } \\
\text { infiltrada por aluminato } \\
\text { de magnésio }\end{array}$ & $280-380$ & $\begin{array}{l}\text { Coroa unitária anterior, } \\
\text { inlay, onlay e faceta. }\end{array}$ \\
\hline $\begin{array}{l}\text { Sistema cerâmico } \\
\text { fresado }\end{array}$ & $\begin{array}{l}\text { Procera } \\
\text { AllCeram }\end{array}$ & $\begin{array}{c}\text { Alumina pura } \\
\text { densamente sinterizada }\end{array}$ & $487-699$ & $\begin{array}{l}\text { Coroa unitária anterior e } \\
\text { posterior, PPF de } 3 \text { elementos } \\
\text { (até } 1^{\circ} \text { molar), supra-estrutura } \\
\text { unitária para prótese sobre } \\
\text { implante. }\end{array}$ \\
\hline $\begin{array}{l}\text { Sistema cerâmico } \\
\text { fresado }\end{array}$ & Cercon & Y-TPZ & $900-1200$ & $\begin{array}{c}\text { Coroa unitária anterior e } \\
\text { posterior e PPF de } 3 \text { a } 8 \\
\text { elementos. }\end{array}$ \\
\hline $\begin{array}{l}\text { Sistema cerâmico } \\
\text { fresado }\end{array}$ & Lava & Y-TPZ & $900-1200$ & $\begin{array}{l}\text { Coroa unitária anterior e } \\
\text { posterior e PPF de } 3 \text { a } 4 \\
\text { elementos. }\end{array}$ \\
\hline
\end{tabular}

Portanto, para indicar adequadamente cada sistema cerâmico deve ser avaliada primeiramente a região da reabilitação, sendo que as propriedades ópticas do material são mais importantes que as altas resistências à flexão para as restaurações anteriores. Já as áreas posteriores necessitam de alta resistência flexural para suportar as cargas mastigatórias mais elevadas. Nesse caso, materiais mais opacos podem ser selecionados, já que a estética não é fator primordial para decidir o material a ser escolhido. Além das propriedades mecânicas e ópticas deve ser verificada a capacidade de adesão do material ao dente, pois como foi verificado, quanto mais resistente é o material mais difícil é a realização da cimentação adesiva da peça, devido à dificuldade do condicionamento de superfície da cerâmica.

\section{CONCLUSÕES}

Dispõem-se atualmente de materiais cerâmicos com elevadas propriedades mecânicas, que possibilitam a confecção de restaurações cerâmicas livres de metal tanto na região anterior como na região posterior. Quanto maior a resistência mecânica do material maior é a dificuldade em realizar a cimentação adesiva entre o dente e a restauração cerâmica.

A indicação de cada sistema cerâmico deve ser feita de maneira criteriosa, levando em consideração não apenas a resistência mecânica do material como também a região que deverá ser restaurada e a forma de união entre o dente e a restauração, a fim de garantir a longevidade do tratamento. 


\section{REFERÊNCIAS}

[1] A. Della Bona, C. Shen, K. J. Anusavice, Dent. Mater. 20 (2004) 338.

[2] J. R. Kelly, I. Nishimura, S. D. Campbell, J. Prosthet. Dent. 75, 1 (1996) 18.

[3] C. Land, Dent. Cosmos 45 (1903) 615.

[4] J. W. McLean, T. H. Hughes, Br. Dent. J. 119 (1965) 251.

[5] J. W. McLean, I. R. Sced, Aust. Dent. J. 21 (1976) 119.

[6] R. G. Craig, Materiais dentários restauradores, $11^{\text {a }}$ Ed.,

Ed. Santos, S. Paulo, SP (2004) 575.

[7] A. Della Bona, K. J. Anusavice, Int. J. Prosthodont. 15, 2 (2002) 159.

[8] K. J. Anusavice, Phillips' Science of Dental Materials, $10^{\text {th }}$ Ed., Philadelphia, W.B. Saunders Company (1996) 583.

[9] J. W. McLean, The science and art of dental ceramics, vol II: bridge design and laboratory procedures in dental ceramics, Ed. Rio de Janeiro:Quintessence, Rio de Janeiro, RJ (1980).

[10] E. Miyashita, A. S. Fonseca, Odontologia estética: o estado da arte. $1^{\text {a }}$ Ed. Artes Médicas, S Paulo, SP (2004).

[11] T. R. Walton, Int. J. Prosthodont. 15 (2002) 439.

[12] G. Libby, M. R. Arcuri, W. E. La Velle, L. Hebl, J. Prosthet. Dent. 78 (1997) 127.

[13] R. A. Giordano, Gen. Dent. 48, 1 (1999) 38.

[14] J. P. Moffa, A. A. Lugassy, J. A. Ellison, J. Dent. Res. 65 (1986) 343.

[15] R. R. Seghi; J. A. Sorensen, Int. J. Prosthodont. 8, 3 (1995) 239.

[16] R. A. Giordano, L. Pelletier, S. Campbell, R. Pober, J. Prosthet. Dent. 73 (1995) 411.

[17] J. A. Sorensen, T. J. Torres, S. K. Kang, S.P. Avera, J. Dent. Res. 69 (1990) 279.

[18] J. A. Sorensen, S. K. Kang, S. M. Kyomen, S. P. Avera, R. Faulkner, J. Dent. Res. 70 (1991) 540.

[19] W. C. Wagner, T. M. Chu, J. Prosthet. Dent. 76, 2 (1996) 140 .

[20] R. R. Seghi, I. L. Denry, S. F. Rosenstiel, J. Prosthet. Dent. 74 (1995) 145.

[21] J. W. McLean, Br. Dental J. 123 (1967) 571.

[22] E. A. McLaren, Compend. Contin. Educ. Dent. 19 (1998) 307.

[23] E. A. McLaren, S.N. White, Quintessence Dent. Technol. 23 (2000) 63.

[24] M . J. Heffernan, S. A. Aquilino, A. M. Diaz-Arnold,
D. R. Haselton, C. M. Stanford, M. A. Vargas, J. Prosthet. Dent. 88 (2002) 10.

[25] K. G. Olsson, B. Furst, B. Andersson, G. E. Carlsson, Int. J. Prosthodont. 16 (2003) 150.

[26] M. J. Suarez, J. F. Lozano, M. Paz Salido, F. Martinez, Int. J. Prosthodont. 17 (2004) 35.

[27] B. S. Segal, J. Prosthet. Dent. 85, 6 (2001) 544.

[28] J. K. Dong, H. Luthy, A. Wohlwend, P. Scharer, Int. J. Prosthodont. 5 (1992) 9.

[29] J. R. Mackert, C. M. Russell, J. Dent. Res. 74 (1995) 166.

[30] M. Schweiger, W. Holand, M. Frank, H. Drescher, V. Rheinberger, Quintessence Dent. Technol. 22 (1999) 143.

[31] J. A. Sorensen, Quintessence Dent. Technol. 22 (1999) 153.

[32] J. F. Esquivel-Upshaw, K. J. Anusavice, H. Young, J. Jones, C. Gibbs, Int. J. Prosthodont. 17 (2004) 469.

[33] A. J. Raigrodski, J. Prosthet. Dent. 92, 6 (2004) 557.

[34] D. B. Evans, W. J. O’Brien, Int. J. Prosthodont. 12, 1 (1999) 38.

[35] P. Ottl, A. Piworwarczyk, H. C. Lauer, E. A. Hegenbarth, Int. J. Peridontics Restorative Dent. 20, 2 (2000) 151.

[36] J. A. Carollo, Compend. Contin. Educ. Dent. 24 (2003) 218.

[37] B. Hager, A. Oden, B. Andersson, L. Andersson, J. Prosthet. Dent. 85, 3 (2001) 231.

[38] A. Oden, M. Andersson, I. Krystek-Ondracek, D. Magnusson, J. Prosthet. Dent. 80 (1998) 450.

[39] C. Piconi, G. Maccauro, Biomaterials 20 (1999) 1.

[40] D. Suttor, K. Bunke, S. Hoescheler, H. Hauptmann, G. Hertlein, Int. J. Comput. Dent. 4 (2001) 195.

[41] R. G. Luthardt, O. Sandkuhl, B. Reitz, Eur. J. Prosthodont. Restor. Dent. 7 (1999) 113.

[42] J. A. Sorensen, Quintessence Dent. Technol. 26 (2004) 57.

[43] P. Christel, A. Meunier, M. Heller, J. P. Torre, C. N. Peille, J. Biomed. Mater. Res. 23 (1989) 45.

[44] 3M/ESPE. Lava All-Ceramic System. (Instruções técnicas do fabricante).

[45] J. R. Kelly, J. A. Tesk, J. A. Sorensen, J. Dent. Res. 74 (1995) 1253.

[46] L. L. Miller, Dent. Clin. North Am. 21 (1977) 699.

[47] A. Della Bona, R. van Noort, Am. J. Dent. 11, 6 (1998) 276.

[48] M. Kern, V. P. Thompson, J. Prosthet Dent. 73, 3 (1995) 240.

(Rec. 30/10/2007, Rev. 29/02/2008, Ac. 04/04/2008) 